\title{
High-pressure Sodium Radiation during Off-peak Nighttimes Increases Cut Rose Production and Quality
}

\author{
Douglas A. Hopper ${ }^{1}$ \\ Department of Horticulture and Landscape Architecture, Colorado State \\ University, Fort Collins, CO 80523
}

Additional index words. high-intensity discharge lamps, light, Rosa hybrida, supplemental radiation

\begin{abstract}
One-year-old plants of four cut rose (Rosa hybrida L.) cultivars were grown under either natural or supplemental irradiance for $\mathbf{4}$ months during the winter in Colorado. Supplemental irradiance with high-pressure sodium (HPS) lamps was supplied at 100 $\mu \mathrm{mol} \cdot \mathrm{m}^{-2} \cdot \mathrm{s}^{-1}$ for $10 \mathrm{~h}$ each night during off-peak electrical use periods. Total cut flower yield, stem length, and fresh weight of individual flowers were recorded. The number of flowers produced and fresh weight increased for all cultivars under the supplemental irradiance treatment. Flower count, stem length, and fresh weight showed significant differences among the four 4-week production periods; production differences were promoted through pinches of two stems per plant to time for holiday peaks. When production was highest, stem length and fresh weight were lower, most likely due to redistribution of the limited carbohydrate pool during the winter.
\end{abstract}

Increased growth of the commercial rose under increased levels of solar or supplemental photosynthetic photon flux (PPF) has been documented, particularly under environmental conditions of limiting PPF (Aikin and Hanan, 1975; Bozarth et al., 1982; Cathey and Campbell, 1979; Lieth et al., 1987; Moe, 1972; Tsujita, 1982). Particularly important, Tsujita (1991) found that when artificial supplemental PPF above the light compensation point during the normal night period increased dry weight gain, overall flower yield and quality increased in the low PPF of winter in northern climates. Separate work with a simplified

Received for publication 26 Oct. 1995. Accepted for publication 14 May 1996. Funding was provided by the Colorado Agricultural Experiment Station (Project 747). I gratefully acknowledge grants from the Colorado Greenhouse Growers' Association and the Colorado Floriculture Foundation for support of this research project. I thank Jackson and Perkins and DeVor Nurseries for supplying the plants for this study. I thank Kennneth L. Goldsberry for providing consulting assistance which enabled proper setup of the greenhouse environment. I also appreciate that GTE Products, Sylvania Lighting Division, donated a portion of the fixtures and 1000W lamps used in conducting this study. Special thanks to the students who assisted with this project: undergraduate students Wes Alexander, Dean Dushack, Lori Guillory, Dan Klahre, Kristin Butler Morton, Mary Smith, Jerry Toll, and graduate student Steven E. Woerner. Additional thanks to retired volunteer Howard Smith and former PERC Greenhouse Manager David Hantz. The cost of publishing this paper was defrayed in part by the payment of page charges. Under postal regulations, this paper therefore must be hereby marked advertisement solely to indicate this fact.

${ }^{1}$ Assistant Professor. rooted cutting system indicated that supplemental high-pressure sodium (HPS) lighting increased the number of flowers produced and decreased time to flowering, but stem and bud size did not increase directly with the PPF level (Rupp and Bugbee, 1990).

Although production increases have been substantiated, commercial rose production also must realize a favorable economic return from the necessary investments. Yield increases of $21 \%$ have been reported (for 'Samantha': $24 \mathrm{~h}$ of $65 \mu \mathrm{mol} \cdot \mathrm{m}^{-2} \cdot \mathrm{s}^{-1}$ ) by Tsujita and Jaio (1990) and of $38 \%$ (for 'Royalty': $10 \mathrm{~h}$ of 130 $\mu \mathrm{mol} \cdot \mathrm{m}^{-2} \cdot \mathrm{s}^{-1}$ ) by Hopper (1991). The economics were addressed by Good and Langhans (1975), contending that net returns of $\$ 3.11$ per $\mathrm{m}^{2}$ for the total greenhouse area reflected a $12.5 \%$ rate of return on investment at a cost of 1.76 cents per $\mathrm{kWh}$, while an increase to 2.9 cents per $\mathrm{kWh}$ would produce zero net returns. However, these results have all depended on differences in response of various cultivars, and the initial investment cost might appear prohibitive if the electrical rate structure did not suggest a sufficiently short payback period. Electricity is typically least costly at the off-peak demand period ( 2100 to $0700 \mathrm{HR}$ ). To further complicate the issue, heat produced by the luminaires may sufficiently offset heating costs to make supplemental irradiation a favorable investment.

Therefore, the responses of several popular rose cultivars in the high-solar-irradiance region of Colorado were evaluated. The objectives were to evaluate: 1) the yield response of four rose cultivars in a naturally lighted fiberglass greenhouse with or without 10-h daily supplemental HPS irradiation and 2) quality of flowering rose shoots, as shown by length and fresh weight, under normal and supplemental irradiance.
This study was conducted in a single fiberglass-covered greenhouse. Six benches $(1.1 \times$ $10.7 \mathrm{~m}$, oriented east-west lengthwise) were designated A to F from north to south; only four benches, B to E, were used to obtain data for this experiment, while edge benches $A$ and F functioned as buffer zones. Plants in benches $\mathrm{C}$ and $\mathrm{D}$ received a 10-h off-peak supplemental radiation treatment [which is defined by the electrical utility company (Public Service of Colorado) as 2100 to $0700 \mathrm{HR}$ for reduced electrical rates] each night beginning 30 Oct. 1991 (day 304) through 29 Feb. 1992, while benches $\mathrm{B}$ and $\mathrm{E}$ functioned as a standard control for comparison. Six 1000-W HPS lamps from GE Sylvania (Sylvania Lighting Division, Denver) were installed on about $3.05 \times$ $3.66-\mathrm{m}$ spacing at 2.14 to $3.05 \mathrm{~m}$ above the plant canopy to provide $100 \mu \mathrm{mol} \cdot \mathrm{m}^{-2} \cdot \mathrm{s}^{-1}$ over the $5.0 \times 7.0-\mathrm{m}$ area. Black cloth screens with white reflective surface toward the lamps were drawn to isolate the treatments while lamps were on at night. Under each treatment plot, measurements were made with a hand-held PPF meter with an LI-190 sensor (LI-COR, Lincoln, Neb.) to assess overall uniformity of the supplemental irradiance pattern. The distance from lamps to the crop canopy was adjusted to achieve an average level of 100 $\mu \mathrm{mol} \cdot \mathrm{m}^{-2} \cdot \mathrm{s}^{-1}$ for the $10 \mathrm{~h}$ of daily supplementation. Adjustments were made to the fixture spacing and height on 5 Nov. 1991 to produce a more uniform PPF distribution. Two of the lamps on the east end of the house were found unplugged for 3 days in November, but this did not appear to adversely affect the study. Since the day/night temperature set points were determined by a light sensor in an aspirated thermostat at the center of the lighted treatment, the sensor box was covered at night to maintain the set points at $23{ }^{\circ} \mathrm{C}$ day $/ 16^{\circ} \mathrm{C}$ night. Automatic irrigation in the lighted treatment benches was increased to twice daily to offset the added metabolic demands and thereby prevent water stress in the supplemental PPF treatments. The natural lighted control plants were watered only once automatically each morning. Each irrigation provided a constant liquid feed (CLF) nutrient solution with (in mg. $\mathrm{L}^{-1}$ ) $200 \mathrm{~N}, 13 \mathrm{P}, 264 \mathrm{~K}$, and $16 \mathrm{Mg}$. Micronutrients were supplied by soluble trace element mix (STEM) at (in $\mathrm{mg} \cdot \mathrm{L}^{-1}$ ) $0.96 \mathrm{~S}$, $0.22 \mathrm{Cu}, 0.51 \mathrm{Fe}, 0.55 \mathrm{Mn}, 0.0027 \mathrm{Mo}, 0.31$ $\mathrm{Zn}$, and $0.093 \mathrm{~B}$; additional iron was supplied at $0.20 \mathrm{Fe}$ from ethylenediaminetetraacetic acid (EDTA).

Concrete above-ground beds were lined with $0.152-\mathrm{mm}$ black plastic to allow for collection of nutrient solution in further studies. Par-gro medium-grade rockwool (American Clay, Denver) was placed 15-20 cm deep in vbottomed beds and thoroughly moistened before use. Top-grade $(3 \times)$ plants of four cultivars ('Royalty', 'Samantha', 'Sonia', and 'Gabriella') were placed one per $0.093 \mathrm{~m}^{2}$ in groups of 30 per plot, with each $1.07 \times 10.7 \mathrm{~m}$ bench containing four plots (total of 120 plants/ bench). Benches B and C together were considered one block, while benches $\mathrm{D}$ and $\mathrm{E}$ 
were a second block for analysis of experimental results. Planting took place on 16 Sept. 1991 (day of the year: 259). After an initial irrigation, a $70 \%$ shade white plastic tent was placed over the entire length of all the benches for 2 weeks. While tented, a perimeter gates watering system having 1.0-cm nozzles (spaced $60 \mathrm{~cm}$ apart) with semi-circle spray patterns was run for $2 \mathrm{~min}$ three times each day to provide syringing to raise humidity and promote new growth. Buffer benches (A and F) were similarly planted with 'Bridal Pink' and 'Fire and Ice' in Oct. 1991. To increase branching, plants in the study were pinched on 14 Oct. 1991 (day 287), 29 Oct. 1991 (day 303; for Christmas), and 20 Dec. 1991 (day 354; for Valentine's Day). Pinches for the holiday markets were made on two shoots on each plant, with two five-leaflet leaves remaining on each pinched shoot.

Data were collected on roses produced from each plot from Nov. 1991 through Feb. 1992. Each flowering rose shoot was counted and measured for stem length. Fresh weight was recorded for the first 12 stems produced from each plot starting on the first of each month. Total production, stem lengths, and fresh weights for each plot were analyzed according to a split plot design (SPD) with two blocks (north and south side of the greenhouse), supplemental radiation and cultivar as main factors in the whole plot, and period as the subplot. Data were categorized into se- quential 4-week periods starting with week 46 of 1991 and continuing through week 9 of 1992 to approximate equal-length monthly periods. Tukey's honestly significant difference (HSD) determined significant differences among all means.

\section{Results and Discussion}

Supplemental irradiance increased the number of flowers produced and the fresh weight of flowers for all cultivars over all four production periods; however, stem length was not significantly influenced (Tables 1 and 2). Although 'Royalty' and 'Samantha' produced fewer flowers than 'Gabriella', both had longer stems and higher fresh weight than 'Gabriella' (Table 2). This result suggests that although these three cultivars were similar in efficiency of carbohydrate production, a cultivar partitioned carbohydrates to produce either a few large flowers or more, smaller flowers. The exception was 'Sonia', which produced relatively many flowers with intermediate stem length and fresh weight. Our results in Colorado agree with those of Tsujita (1991) in the more northern climate of Guelph, Canada, who found supplemental irradiance to increase flower count and dry weight in winter. However, results of our study differ from those of Rupp and Bugbee (1990), where flowering shoot size was not increased with higher irradiance, yet our study found increased fresh

Table 1. Analysis of variance (ANOVA) of mean number of rose flower stems produced, stem length, and fresh weight under natural and supplemental irradiance conditions. Each mean includes counts of the flowers produced during a 4-week period by 30 plants (each from two benches, each one a block of the same treatment) from Nov. 1991 to Mar. 1992. There were four data collection periods.

\begin{tabular}{|c|c|c|c|c|}
\hline \multicolumn{5}{|c|}{ ANOVA mean squares } \\
\hline Source & df & No. flowers & Stem length & Fresh wt \\
\hline Block (B) & 1 & 354 & 8.91 & 32.9 \\
\hline Irradiance (I) & 1 & $4596^{* * *}$ & 0.0760 & $163^{* * *}$ \\
\hline Cultivar (C) & 3 & $2851^{* * *}$ & $778^{* * *}$ & $372^{* * *}$ \\
\hline $\mathrm{I} \times \mathrm{C}$ & 3 & 277 & 7.56 & 1.20 \\
\hline Error a & 7 & 66.9 & 12.1 & 4.63 \\
\hline Period (P) & 3 & $2246^{* * *}$ & $413^{* * *}$ & $180^{* * *}$ \\
\hline $\mathrm{P} \times \mathrm{I}$ & 3 & 267 & 23.5 & 16.3 \\
\hline $\mathrm{P} \times \mathrm{C}$ & 9 & 633 & 17.5 & 17.0 \\
\hline $\mathrm{P} \times \mathrm{I} \times \mathrm{C}$ & 9 & 146 & 7.42 & 3.71 \\
\hline Error b & 88 & 196 & 44.9 & 26.3 \\
\hline Total & 127 & --- & --- & --- \\
\hline Coefficient of variation & & 40.8 & 15.1 & 28.2 \\
\hline
\end{tabular}

${ }^{* * *}$ Significant at $P \leq 0.001$.

Table 2. Mean rose flower stems produced, stem length, and fresh weight under natural and supplemental irradiance conditions. Each mean includes counts of the flowers produced in a 4-week period by 30 plants (each from two benches: each one a block of the same treatment) from Nov. 1991 to Mar. 1992. There were four data collection periods.

\begin{tabular}{|c|c|c|c|c|c|c|}
\hline \multirow{3}{*}{$\begin{array}{l}\text { Growth } \\
\text { response }\end{array}$} & \multicolumn{6}{|c|}{ Measured response to supplemental irradiance or cultivar } \\
\hline & \multicolumn{2}{|c|}{ Irradiance $^{\mathrm{z}}$} & \multicolumn{4}{|c|}{ Cultivar $^{\mathrm{y}}$} \\
\hline & Natural & Supplemental & Royalty & Samantha & Sonia & Gabriella \\
\hline Number of flowers & $28.3 \mathrm{a}^{\mathrm{x}}$ & $40.3 \mathrm{~b}$ & $26.8 \mathrm{a}$ & $26.0 \mathrm{a}$ & $39.8 \mathrm{ab}$ & $44.8 \mathrm{~b}$ \\
\hline Stem length $(\mathrm{cm})$ & $44.7 \mathrm{a}$ & $44.7 \mathrm{a}$ & $49.4 \mathrm{c}$ & $47.7 \mathrm{bc}$ & $43.4 \mathrm{ab}$ & $38.4 \mathrm{a}$ \\
\hline Fresh weight (g) & $17.1 \mathrm{a}$ & $19.4 \mathrm{~b}$ & $22.1 \mathrm{c}$ & $18.9 \mathrm{bc}$ & $18.3 \mathrm{~b}$ & $13.8 \mathrm{a}$ \\
\hline
\end{tabular}

${ }^{2}$ Weekly means were compared across cultivars for number of flowers produced from 30 plants for each irradiance level.

'Weekly means were compared across irradiance levels for number of flowers produced from 30 plants for each cultivar.

${ }^{x}$ Mean separation in rows within group headings by Tukey's honestly significant difference at $P \leq 0.001$.

weight with increased irradiance. The difference in response may be due to the different growing systems used, since Rupp and Bugbee used smaller single-stemmed plants with insufficient leaf surface area to produce additional carbohydrates that might increase the flower size near the end of the growth cycle. Work by Lieth and Pasian (1991) indicates that PPF attenuates quickly further down into the rose plant canopy, so the benefit of increased PPF intensity is most likely realized by the shoot tips above the top two leaves on a shoot. Plants in our study were less than 1 year old, and although responses may differ as plants reach a full canopy, the findings of Lieth and Pasian(1991) suggest that the canopy on the 1-year-old plants captures the most significant PPF available, and any additional undercanopy may have less effect.

Production trends of flowers when combining all four cultivars were evident in response to time between pinching and timing of crops for the holidays of Christmas and Valentine's Day (Fig. 1). Significantly more flowers were obtained for Valentine's Day in period 3, timed with commercial production to occur in week 5 of the year (Fig. 1A). Stems were longer and fresh weight higher in period 4 than in period 1 (Fig. $1 \mathrm{~B}$ and C), possibly due to the increasing natural solar irradiance during period 4 . Interestingly, the supplemental irradiance did not appear sufficient to alter these quality measures during periods 1 to 3 of winter. As production peaked in period 3 , the trend was toward decreases in stem length and fresh weight as the number of stems increased. This trade-off between the number of stems and the total size of each suggests the total available carbohydrates produced were partitioned similarly between the number of growing meristems. A similar result was presented in data from Tsujita (1982), where supplemental irradiance increased the number of flowers produced, yet the flowers had significantly shorter stems and lower flowering shoot weight.

Overall, supplemental irradiance from HPS lamp usage during off-peak demand periods increased the number of cut roses produced and fresh weight of the roses in a high-naturalsolar irradiance location similar to what one would observe from normal seasonal fluctuations, but natural solar irradiance still seemed to have a greater influence when compared to the level of supplemental PPF used. This finding is particularly important in high-solarirradiance regions, such as Colorado, since increased electrical costs from supplemental irradiance may offset any economic return through increased production from lamp usage, even if the lamps are used only in the lowpriced, off-peak demand period. Even growers in such high-irradiance areas must analyze costs closely, since the marginal increase in the number of cut roses produced from supplemental irradiance may not be economically beneficial when compared to other areas of the world where natural seasonal solar irradiance levels yield more preferred-quality long stems and high fresh weights, but without the additional costs due to lamp usage. 


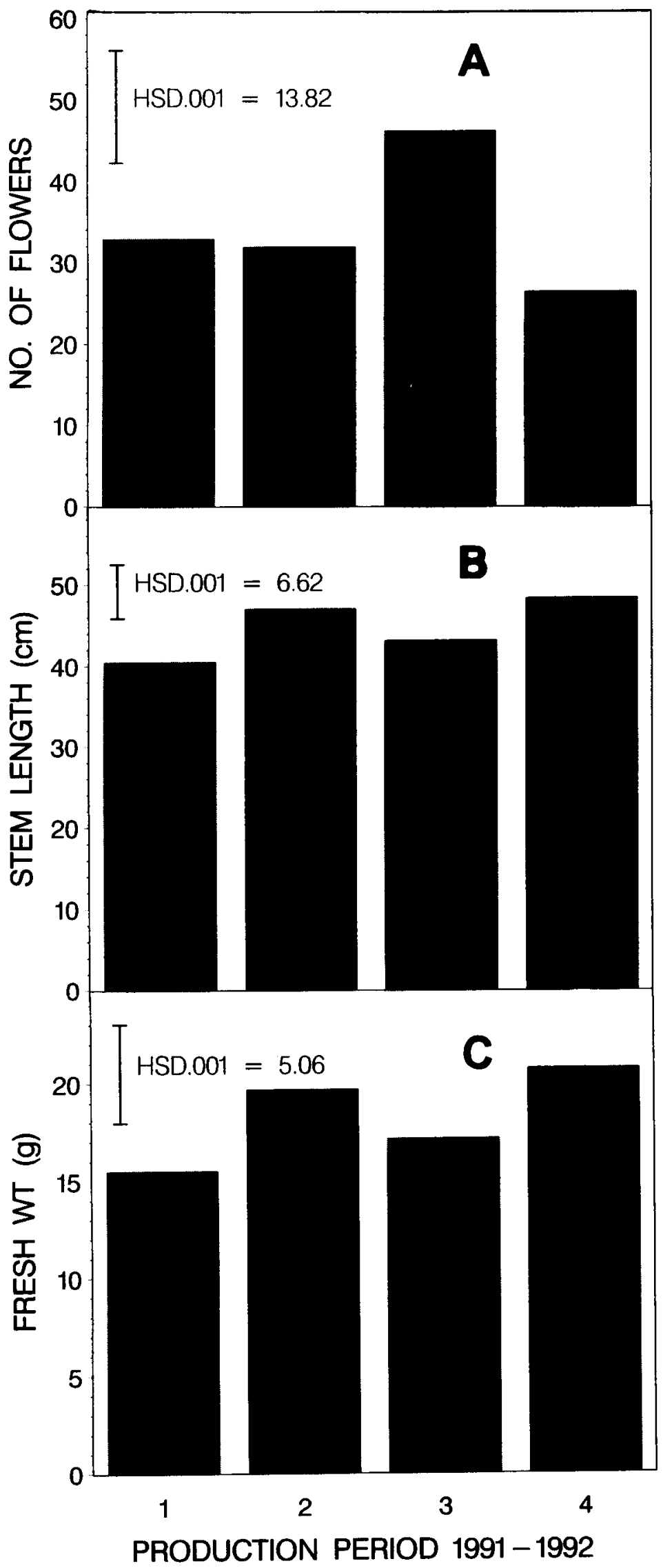

Fig. 1. Comparison of (A) number of flowers produced, $(\mathbf{B})$ stem length, and $(\mathbf{C})$ fresh weight of an individual flower for each of the 4-week periods starting with week 46 of 1991 through week 9 of 1992 . Number of flowers are means across cultivars of production from 30 plants. Significance indicated by Tukey's honestly significant difference (HSD) at $P=0.001$.

\section{Literature Cited}

Aikin, W.J. and J.J. Hanan. 1975. Photosynthesis in the rose; Effect of light intensity, water potential and leaf age. J. Amer. Soc. Hort. Sci. 100:551553.

Bozarth, C.S., R.A. Kennedy, and K.A. Schekel. 1982. The effects of leaf age on photosynthesis in rose. J. Amer. Soc. Hort. Sci. 107:707-712.

Cathey, H.M. and L.E. Campbell. 1979. Relative efficiency of high- and low-pressure sodium and incandescent filament lamps used to supplement natural winter light in greenhouses. J. Amer. Soc. Hort. Sci. 104:812-825.

Good, D. and R. Langhans. 1975. Cost and returns of high intensity discharge lighting in rose production. Cornell Univ. Agr. Expt. Sta. Bul. Agr. Econ. Ext. 75-2.

Hopper, D.A. 1991. Supplemental lighting for improved rose growth and quality. Final Rpt. to Colorado Greenhouse Growers' Assn. and Public Service of Preliminary Study. June.

Lieth, J.H. and C.C. Pasian. 1991. Automated optimization of rose production: Light attenuation and calculation of rose crop canopy photosynthesis. Roses Inc. Bul. Joseph H. Hill Foundation Prog. Rpt. January, p. 35-40.

Lieth, J.H., C.C. Pasian, and M.S. Reid. 1987. Automated optimization of rose production; Data collection for rose leaf photosynthesis model development. Roses Inc. Bul. June, p. 57-63.

Moe, R. 1972. Effect of daylength, light intensity, and temperature on growth and flowering in roses. J. Amer. Soc. Hort. Sci. 97:796-800.

Rupp, L.A. and B. Bugbee. 1990. High intensity rose production using rooting cuttings. Roses Inc. Bul. Joseph H. Hill Foundation Prog. Rpt. February, p. 41-51.

Tsujita, M.J. 1982. Flower cutting practices for greenhouse roses receiving supplemental irradiation. HortScience 17:44-45.

Tsujita, M.J. 1991. Environmental parameters for computer-controlled greenhouses. Roses Inc. Bul. Joseph H. Hill Foundation Prog. Rpt. February, p. 53-57.

Tsujita, M.J. and J. Jaio. 1990. Environmental parameters for computer-controlled greenhouses. Roses Inc. Bul. Joseph H. Hill Foundation Prog. Rpt. p. 51-56. 